\title{
Time for a rethink of treatment for patients with depression in primary care
}

The publication of a paper showing that mindfulness-based cognitive therapy prevented relapse of depression in a group of primary care patients at high risk of relapsing, is another reminder of the importance about these nonpharmacological therapies and should make us rethink what we are doing with treatment of depression in primary care. ${ }^{1}$

Cognitive therapy encourages patients to concentrate on their thinking patterns and become aware of their thoughts, so that they eventually introduce more helpful thoughts into their minds, while mindfulness refers to looking at our thoughts with increasing interest and acceptance.

The current approach for many is to suggest a follow-up appointment within 2 weeks, ${ }^{2}$ and practitioners may have no system to check if this happens or not. Kay McKall in her wonderful article on 'An Insider's Guide to Depression' reminds us that patients with depression may not be thinking clearly and thus may not make a return visit, having neither the energy nor the inclination. ${ }^{3}$ A strategy for the alert practitioner is to book the next appointment while the patient is present, so that if they do not show up there is a reminder for the practitioner or team to contact them. 'Active monitoring' is an important part of current guidelines, and we must find practical ways to implement it.

McKall also reminds us that we should arrange visits more often. Her words are 'See us frequently at first. A week is a long time in a Dali landscape. Three weeks are almost unimaginable'. Current guidelines suggest review in 1-2 weeks or even longer in milder cases. Perhaps appointments twice in the first week with regular calls from the practice nurse in between could be a more intensive starting point?

Wagner and Simon defined high-quality care as the choice of treatment, and adequate intensity of treatment and follow- up. ${ }^{4}$ Surely our goal is to treat until remission? Would we stop following up patients with diabetes when they became 'better than they were before'? Work from the US suggests that patients with depression in primary care get less than optimal drug therapy and have inconsistent follow-up. 5

Collaborative care is an important part of depression management, and incorporates the skills of different members of the healthcare team, including a case manager. ${ }^{67}$ In fact, case management has been shown to be one of the interventions that consistently improves patient outcomes in depression in primary care. ${ }^{67}$

As well as improving our follow-up protocols, we need to update our management. Our faith in antidepressants is unwarranted. The median proportion of those with an improvement is $60 \%$ on selective serotonin reuptake inhibitors in primary care, but the median placebo rate is $46 \%$ giving a 'number needed to treat' of seven. ${ }^{8}$ In other words, the majority of patients do not get better because of medication, although about half get a placebo response.

To think about psychological approaches as frontline treatments, we must be aware of the range of possibilities that we can offer patients with depression. While cognitive behavioural therapy (CBT) has not been shown to be effective in primary care, it has been effective in secondary care. ${ }^{9}$ The recent Improving Access to Psychological Therapies Programme in the UK will ensure that psychological treatment is more freely available, with a plan for 3600 new therapists by $2010 / 11 .{ }^{10}$ This initiative has been welcomed by patients, and will offer them more treatment choices.

Some patients may prefer to receive treatment within the practice. Either GPs or practice nurses can have more extensive training, or those with more extensive training can be employed. Another option is computerised CBT which can be offered before face-to-face CBT. ${ }^{2,11}$ Problem solving therapy has been shown to be effective in primary care and more needs to be made of it. ${ }^{2}$

Seligman and colleagues' first 'happiness' randomised controlled trial looking at internet-based interventions for people with depressive symptoms, showed us that even a simple exercise involving writing down three things that went well each day and their causes for 1 week (a gratitude diary), can decrease these symptoms for 6 months. ${ }^{13}$ There are ways that we can manage the time required to use tools other than medication. We can book longer appointments, activate other members of the team, or perhaps work with groups of patients.

It is also encouraging that some new initiatives are taking a population mental health approach rather than solely focusing on treating individuals who are unwell. ${ }^{14}$ This reminds us to take a more holistic view, and emphasises the importance of positive mental health and a mentally healthy community. ${ }^{15}$

There is evidence that the prognosis for depression is not good, with about $50 \%$ of patients still symptomatic at 1 year in spite of antidepressant medication. ${ }^{13}$

The success of group mindfulnessbased cognitive therapy by Kuyken et al paves the way for a new approach. ${ }^{1}$ Once patients are in remission or improved, an offer of group mindfulness-based cognitive therapy could help guard against relapse. The current recommendation is to suggest this for patients at significant risk of relapse. ${ }^{1}$ As well as relapse prevention for those who have been depressed, we need to think about preventative strategies for our patients at risk - or perhaps for all of our patients, given the prevalence of the condition. ${ }^{16}$ 
It is clear that antidepressant medication has its limitations. We now have many psychological treatments and the evidence for many nonpharmacological approaches for depression is growing. In conjunction with medication, these should now be a mainstay of treatment, and all practitioners should be equipped to offer patients a range of options, either by upskilling the practice staff or by referral. The evidence for mindfulness-based cognitive therapy adds to this argument.

While the concept of adjunctive approaches to medication for depression is not new, we must also consider the long-term and preventive issues, and treat depression as a chronic relapsing condition. Ongoing intervention has been shown to improve symptoms and functioning significantly and to increase remission. ${ }^{17}$ All of this may require an openesss in primary care to consider such new ways of healthcare delivery.

\section{Bruce Arroll,}

Professor, Head of Department of General Practice and Primary Health Care, University of Auckland, Auckland, New Zealand.

\section{Fiona Moir}

Senior Lecturer in Mental Health and Communication Skills, Department of General Practice and Primary Health Care, University of Auckland, Auckland, New Zealand.

\section{Provenance}

Freely submitted; peer reviewed.

\section{REFERENCES}

1. Kuyken W, Byford S, Taylor RS, et al. Mindfulnessbased cognitive therapy to prevent relapse in recurrent depression. J Consult Clin Psychol 2008; 76(6): 966-978.

2. National Institute for Health and Clinical Excellence. Depression: the treatment and management of depression in adults. National clinical practice guideline 90 . London: National Insititute for Health and Clinical Excellence, 2009.

3. McKall K. An insider's guide to depression. BMJ 2001; 323(7319): 1011. [Personal view]

4. Wagner EH, Simon GE. Managing depression in primary care. BMJ 2001; 322(7289): 746-747. [Editorial]

5. Lin EH, Katon WJ, Simon GE, et al. Low-intensity treatment of depression in primary care: is it problematic? Gen Hosp Psychiatry 2000; 22(2): 78-83.

6. Chew-Graham CA, Lovell K, Roberts R, et al. A randomised controlled trial to test the feasibility of a collaborative care model for the management of depression in older people. Br J Gen Pract 2007; 57(538): 364-370

7. Unützer J, Katon W, Callahan CM, et al. Collaborative care management of late-life depression in the primary care setting: a randomized controlled trial. JAMA 2002 288(22): 2836-2845.

8. Arroll B, Elley CR, Fishman T, et al. Antidepressants versus placebo for depression in primary care. Cochrane Database Syst Rev 2009; (3): CD007954.

9. King M, Davidson O, Taylor F, et al. Effectiveness of teaching general practitioners skills in brief cognitive behaviour therapy to treat patients with depression: randomised controlled trial. BMJ 2002; 324(7343): 947-950.

10. National Health Service. Improving access to psychological therapies, 2010. http://www.iapt.nhs.uk/ (accessed 23 Feb 2010)

11. Proudfoot J, Goldberg D, Mann A, et al. Computerized, interactive, multimedia cognitive-behavioural program for anxiety and depression in general practice. Psychol Med 2003; 33(2): 217-227.

12. Mynors-Wallis LM, Gath DH, Lloyd-Thomas AR,
Tomlinson D. Randomised controlled trial comparing problem solving treatment with amitriptyline and placebo for major depression in primary care. $B M J$ 1995; 310(6977): 441-445.

13. Seligman ME, Steen TA, Park N, Peterson C. Positive psychology progress: empirical validation of interventions. Am Psychol 2005; 60(5): 410-421.

14. Cross-government strategy: Mental Health Division. New horizons: a shared vision for mental health. London: Department of Health, 2010. http://www.dh.gov.uk/en/Publicationsandstatistics/Publ ications/PublicationsPolicyAndGuidance/DH_109705 (accessed 5 Aug 2010).

15. Tennant R, Joseph S, Stewart-Brown S. The Affectometer 2: a measure of positive mental health in UK populations. Qual Life Res 2007; 16(4): 687-695.

16. MaGPIe Research Group. The nature and prevalence of psychological problems in New Zealand primary healthcare: a report on Mental Health and General Practice Investigation (MaGPIe). NZ Med J 2003; 116(1171): U379.

17. Rost K, Nutting P, Smith JL, Elliott CE, Dickinson M. Managing depression as a chronic disease: a randomised trial of ongoing treatment in primary care. BMJ 2002; 325(7370): 934 .

DOI: 10.3399/bjgp10X515331

ADDRESS FOR CORRESPONDENCE

\section{Bruce Arroll}

Department of General Practice and Primary Health Care, University of Auckland, Private Bag 92019, Auckland, New Zealand.

E-mail b.arrol/@auckland.ac.nz 